\title{
A DECADÊNCIA DA CIDADE EUROPÉIA: tendência social ou repetição de uma figura retórica?
}

\author{
Martin Gegner*
}

\begin{abstract}
Resumo: Há décadas, a sociologia urbana discute a "decadência da cidade européia". Nas diagnoses de teóricos como Saskia Sassen ou Manuel Castells, a cidade européia é descrita como conceito antiquado que não tem futuro nas condiçoẽs da globalização. Ultimamente, na Alemanha, se pronuncia um novo sintoma desse desenvolvimento: o "encolhimento da cidade". De fato, os dados demográficos indicam uma diminuacão da população metropolitana. Mas... será que isso significa uma decadência? Em uma revisão crítica da sociologia urbana alemã contempôranea, o artigo discute se se trata de uma tendência social ou apenas mais uma variacão de uma figura retórica de uma disciplina científica em crise.
\end{abstract}

Palavras-chave: cidade européia, urbanismo, teoria social.

\section{Introdução}

A retórica da decadência ou do fim da cidade européia não é nada nova. Já no final do Século XIX, a crítica contemporânea lamentou a reestruturação de Paris segundo os planos de Haussmann como o declínio da cidade (Barthélemy, 1861; Blanqui, 1885; Fournel, 1868). A rua, antes um lugar dos flaneurs e da comunicação imediata, se tornava cada vez mais um lugar de transferência, um lugar que devia ser superado o mais rápido possível. Com o

\footnotetext{
* Doutorando em Sociologia na Universidade Téchnica de Berlim; docente na Universidade Humboldt de Berlim, no Departamento da Sociologia Urbana.

Este artigo é uma versão de uma palestra apresentada no Seminário de Sociologia da Universidade de Brasília, em 20 de junho de 2005, em português com o apoio de Dr. Marcel Vejmelka e Vanessa Domingues Silva, Berlim.

Artigo recebido em 15 mar. 2005 e aprovado em 15 jun. 2006.
} 
surgimento dos meios de transporte em massa, por um lado, e do deslocamento da vida pública para o nível simbólico dos jornais, por outro, parecia que estava decaindo um ou, como pensam alguns, o critério específico do espaço público realizado na cidade. Richard Sennett (1974) descreveu esse processo de maneira impressionante, que vale igualmente para as maiores metrópoles daquela época: Londres, Paris e Berlim.

A reestruturação da cidade européia no final do Século XIX tinha várias razões. Os poderes queriam não só impedir rebeliões e revoluções, além de mostrar a grandeza e a beleza das capitais para a concorrência imperialista, mas também reagir de uma maneira funcionalista às mudanças estruturais, quer dizer, ao crescimento enorme da população. ${ }^{1}$ Essas concepções foram sustentadas pelas instâncias de planejamento das cidades. Já mencionamos o nome de Haussmann. Em Berlim foram os Conselheiros de Urbanismo James Hobrecht, no final do Século XIX, e Martin Wagner (Wagner 1929a, b), no início do Século XX, que planejavam e mandavam realizar tanto a construção residencial dentro da cidade quanto o trânsito e a infra-estrutura restante, que Reulecke (1985, p. 56) chama de "tecnologia urbana".

A essa modernização das cidades européias seguiu-se, nos anos 20, uma radicalização da arquitetura. Destacam-se as idéias do arquiteto suíço Le Corbusier, cujo programa de arquitetura modernista estava ligado a transformações urbanísticas radicais. Isto ficou documentado na Carta de Atenas (CIAM, 1943), mas mais claro em um livro de Le Corbusier sobre o planejamento urbano, publicado em 1929. Se declararam os elementos essenciais do urbanismo modernista. Segundo eles, a cidade deveria funcionar como uma máquina, dividida em diferentes esferas funcionais, ligadas pelo trânsito contínuo. Le Corbusier (1929, p. 35) definiu o sentimento moderno como "um espírito da geometria, um espírito da construção e da síntese. Exatidão e ordem são as suas condições básicas". 
Assim, ficou evidente que as cidades crescidas desde a Idade Média representavam um obstáculo para o programa. Conseqüentemente, Le Corbusier (1929, p. 83) pensava em soluções que previam "arrasar o centro das cidades e reconstruí-lo, e que também se deveria arrasar o cordão sujo dos subúrbios". Em muitas partes da Europa a guerra fez isto, de modo que a Carta de Atenas, quando foi publicada, em 1943, como documentação do IV Congresso Internacional da Arquitetura Moderna (CIAM), realizado em 1933, estava disponível como uma opção para orientar a reconstrução das cidades na época pós-guerra.

Mesmo assim, o programa modernista não foi implementado na Europa com tanto radicalismo como, por exemplo, em Brasília. Tanto na Europa ocidental quanto na oriental, durante as primeiras duas décadas do pós-guerra, a pauta era a reconstrução das cidades utilizando a sustância de construção ainda existente e seguindo os traçados dados das cidades. A construção moderna não foi integrada de modo geral no urbanismo. Exceções foram o modelo da cidade socialista, com umas fundações completamente novas, como ocorreu na Alemanha em Eisenhüttenstadt, Schwedt e nos projetos de prestígio na capital da Alemanha oriental, em Berlim oriental, por exemplo na avenida Stalinallee. O mundo ocidental reagiu a este último projeto com um novo bairro em Berlim ocidental, o Hansaviertel, do qual participaram também Le Corbusier e Oscar Niemeyer de maneira decisiva.

A modernização das cidades da Europa ocidental, entretanto, se orientou pelo exemplo do "sonho americano" (Knie, Marz, 1997, p. 13), e se iniciou com a entrada em massa dos automóveis nas cidades. Desde o início dos anos 60, o trânsito automobilístico crescia consideravelmente em todos os países da Europa ocidental. Tentavase corresponder a essa expressão da Modernidade com a construção de grandes magistrais, de autovias urbanas e com o deslocamento do bonde para debaixo da terra. Já nos anos 60, cientistas sociais alemães denunciaram a força destrutiva dessa arquitetura do trânsito. Alexander Mitscherlich (1965) analisou no nível psicológico o 
“mal-estar nas cidades"; Hans Paul Bahrdt (1961) criticou que a rua perderia o seu caráter público se servisse exclusivamente como espaço de transferência para veículos blindados de latão. Se não houvesse mais espaços públicos nas cidades, a cidade deixaria de ser cidade. Seria tão somente um agrupamento de edifícios, ruas e pessoas - uma aglomeração.

\section{O discurso atual}

A essa segunda onda da retórica da cidade européia em decadência, seguiu-se, nos anos 80 , uma recuperação da essência da cidade européia. Hartmut Häußermann e Walter Siebel documentaram-na de maneira quase paradigmática no seu livro $O$ novo ser urbano, de 1987. Para eles, o novo ser urbano representa a reconquista dos centros urbanos pelos jovens alternativos. Sob a impressão das casas ocupadas na parte ocidental de Berlim, eles afirmaram que um ambiente estudantil inicialmente subversivo, que invadia prédios destinados ao abatimento, seria o público burguês de amanhã. Cresceu um novo tipo dos moradores nos centros, que não vivem em relações sociais tradicionais, mas em "residências comunitárias" ou como single. A infraestrutura alternativa de lojas ecológicas, iniciativas culturais, bares e artesanato seriam atrativo para os yuppies também. Depois da fase de transferência, o bairro alternativo tornar-se-ia um bairro rico. Outros urbinastas ligavam essa visão crítica do "novo ser urbano" afirmativamente a um programa da "cidade dos caminhos curtos", onde todas as funções da vida moderna - moradia, trabalho, lazer e consumo - seriam acessíveis rapidamente de bicicleta ou a pé (Hoffmann-Axthelm, 1993). Essa reconquista das cidades também significava um renascimento do transporte público e uma redução da construção de estradas e vias expressas. $\mathrm{Na}$ Alemanha, a ferramenta foi implementada como concepção para estabilizar o ambiente no centro da cidade. A intenção era motivar os habitantes alemães jovens e com bons salários a entrar e permanecer nos centros, evitando ao mesmo tempo a entrada de mais migrantes "estrangeiros". 2 
O programa de reurbanização também teve efeitos em outras cidades da Europa ocidental, mas de maneira diferente. Em muitas cidades medievais da Itália, o centro completo foi transformado em área para pedestres, evidentemente e em primeiro lugar, para incentivar o turismo. O redescobrimento do "barrio gotico" em Barcelona, em antecipação das Olimpíadas de 1992, talvez seja o exemplo mais famoso para uma reurbanização do centro antigo da cidade. Mesmo assim, a tendência para a suburbanização continuou também em toda a Europa nos anos 80 . Na periferia das grandes cidades surgiram parques residenciais e shopping centers cada vez maiores. O "novo ser urbano" pode ser comprovado em alguns bairros isolados, mas não é representativo pela totalidade. Entretanto, desta forma se opõe, pela primeira, vez uma retórica da reurbanização à retórica da decadência da cidade européia.

Em meados dos anos 90, mais uma vez a cidade européia pareceu ter chegado ao fim. Manuel Castells (1999) declarou que o espaço urbano "não tinha relevância social". Para ele a sociedade se apresenta já exclusivamente como uma rede de fluxos de meios eletrônicos. Dentro dessa rede, ainda seriam necessárias algumas cidades isoladas a fim de servirem para estúdios de televisão, bolsas de valores e cenários para eventos e espetáculos. Mas a vida pública de uma cidade, a sua identidade, só teria um significado no nível da subcultura. As cidades seriam "lugares", e como tais demasiado estáveis, inflexíveis e imóveis para terem importância no espaço dos fluxos. Como lugares dos fracassados, dos migrantes e do trabalho não teriam importância no espaço público global. Somente as global cities como São Paulo, Nova Iorque e Shangai, na nomenclatura de Saskia Sassen (1991), teriam relevância como pontos nodais para o fluxo global do capital. Dentro da Europa, figurariam entre essas cidades somente Londres, Paris e Moscou; Berlim certamente não.

Mas também nos anos 90 houve tentativas - pelo menos retóricas - de salvar a cidade européia. Sob o lema do New Urbanism se reimportavam conceitos dos Estados Unidos e da Grã-Bretanha que pareciam continuar de forma positiva a tradição da cidade 
européia: uma arquitetura dos detalhes, utilização mista dos bairros com trabalho, arte e gastronomia, tudo ligado por vastas áreas para pedestres que deveriam lembrar as famosas passagens parisienses do Século IX. Nos EUA, o New Urbanism (www.newurbanism. org) se entende como um movimento contra a suburbanização. No continente europeu, entretanto, só uma parte pequena dessas idéias foi realizada. Um exemplo decididamente tributário do New Urbanism, que deveria ser construído no bairro mais antigo de Berlim, depois de cinco anos do início ainda não foi realizado. Ali se encontra hoje um enorme estacionamento em solo lamacento ou poeirento. O New Urbanism é altamente discutido, por exemplo entre dois sociólogos do urbanismo berlinenses conhecidos no Brasil: enquanto Hartmut Häußermann (2001), da Universidade Humboldt, rechaça a concepção por ser uma Disneylândia para ricos e valoriza o New Urbanism como uma reimportação da idéia da cidade européia, Harald Bodenschatz (2005), da Universidade Técnica, acredita que a concepção é uma chance para um renascimento urbano. Bodenschatz argumenta com as experiências positivas de cidades do centro da Inglaterra, como Manchester e Birmingham.

A mais recente metáfora da crise da cidade européia chama-se a "cidade encolhida" (Oswalt, 2004). ${ }^{3}$ Enquanto no mundo todo se tem que contar com o crescimento da população urbana, na "velha Europa", e particularmente na Alemanha, a situação é completamente diferente. Principalmente os municípios do nordeste da Alemanha perderam até um terço da sua população desde a unificação alemã (Spiegel, 2004). Esses habitantes, por motivos econômicos, foram para o sudoeste rico do país, ou, se dispunham dos recursos necessários, seguiram o movimento para os subúrbios. Quer dizer que também a Alemanha tem um problema de pobreza no nordeste. Mas também na maior região urbanizada do país, na região do Ruhr com cerca de 7 milhões de habitantes, se constata uma redução da população nas cidades propriamente ditas. Nessa região, marcada pela mineração e pela indústria do aço, a transformação estrutural tem conseqüências especialmente visíveis. É obvio que o fenômeno das "cidades encolhidas" é ligado com a desendustrialização e a mudança do setor produtivo para outras partes do mundo. Isto quer 
dizer então que Manuel Castells (1999) tem razão quando diz que os lugares do trabalho não têm futuro, prometendo, por outro lado, mais anos de florescimento às metrópoles de serviços?

Na Alemanha, esse quadro em breve será realidade, porque as aglomerações em volta de Munique, Frankfurt e Stuttgart expandemse tanto em termos de poder econômico quanto em número de habitantes (note-se que isto se refere às grande áreas urbanizadas, porque as próprias cidades já estão chegando ao limite de suas capacidades, o que se manifesta em alguns lugares como aluguéis até duas vezes mais altos que em lugares comparáveis em Berlim).

Isto indica que afirmações gerais sobre a cidade européia já são quase impossíveis. Pelo menos é preciso definir exatamente as condições socioeconômicas de determinadas evoluções. Hoje em dia, parece necessário falar de diferentes trilhas de desenvolvimento ou tipologias do desenvolvimento urbano. Também parece que, na Europa, a clássica dicotomia entre cidade e campo já está desatualizada (Lefèbvre, 1970). Porém, o assunto da "cidade encolhida" continuará relevante para a pesquisa, independentemente de esta se chamar sociologia urbana ou planejamento regional.

Mas o que significa a "cidade encolhida" para os seus habitantes? Significa que milhares de apartamentos serão "retirados do mercado", isto é, destruídos, porque não há inquilinos (Bernt, 2004). Significa que os serviços públicos serão reduzidos e cada vez mais privatizados. O transporte público, o abastecimento e saneamento público da água, os lixeiros, tudo isto está sendo questionado em todas as cidades européias. A União Européia pressiona a favor da liberalização de todos os serviços. Ela quer, por exemplo, que a empresa responsável pelo metrô de Paris, a RATP, possa também assumir o transporte público urbano de Berlim. Os municípios e os Estados nacionais se opõem a essas exigências (Bocklet, 2001). Isto delineia um dos mais importantes campos da política no contexto da unificação européia.

Já se pode apresentar exemplos negativos dessa "europeização". Os serviços de água de Berlim, recentemente, foram 
comprados por uma empresa pertencente ao consórcio francês "Vivendi", que era originalmente uma empresa pública, passando a ter, pela primeira vez em 150 anos de existência, um balanço negativo, com um saldo negativo de 150 milhões de euros. Como conseqüência, os preços da água na capital alemã estão aumentando rapidamente: em 2004 os aumentos foram de 15\% (Werle, 2003; TU Berlin, 2004).

Com a redução do número de habitantes, o volume dos serviços públicos até agora oferecidos nas cidades européias também será reduzido. Quase todos os municípios estão considerando como poderiam terceirizar e cortar serviços. Em 2002, quinze das 64 piscinas públicas em Berlim foram fechadas, dez foram alugadas por empresas privadas porque a prefeitura alegou não ter recursos para mantê-las (BBB, 2005). Isto significa preços tão altos que, principalmente, a população mais pobre não poderá pagar a entrada na piscina. A conseqüência será que haverá poucos visitantes, levando as empresas privadas à falência e fazendo com que as piscinas públicas decaiam.

Neste ponto parece que a retórica da decadência da cidade é realmente certeira, porque desde a sua configuração visionária na época de Haussmann, em Paris, e de Hobrecht, em Berlim, os serviços municipais foram a base material do desenvolvimento cultural da cidade. Sem eles a cultura da diferença, que segundo Siebel (2004a) representa a essência da cidade européia, não poderia ter-se espalhado de maneira tão cômoda. $\mathrm{O}$ abastecimento da população com serviços de responsabilidade pública representa o critério substancial para diferenciar a história da cidade européia da norte-americana, da asiática e, também, da brasileira. O seu sucesso baseava-se na existência de uma vontade de controle político na época do grande crescimento urbano, entre 1880 e 1910, assim como das possibilidades da engenharia e tecnologia para dominar as dificuldades resultantes.

As cidades européias ainda vivem com base em suas amplas redes de abastecimento - da água, do transporte público, de gás e luz - com base no grande número de moradias antigamente públicas 
e hoje quase completamente privatizadas - tudo isto criado e configurado no início do Século XX. Hoje não há essa vontade de configuração política. As cidades estão querendo vender a "prata da casa". Negócios de sale-and-lease-back (vender e realugar) de instituições municipais já são a regra.

Com a diminuição dos serviços públicos a partir de base mais elevada parece que as cidades européias estão indo na direção contrária em relação aos municípios brasileiros que, com programas como o "Favela Bairro", no Rio de Janeiro, estão aumentando os serviços para a população urbana a partir de um nível baixo nas áreas periféricas (Bastos, 2004; Pamuk, Cavallieri, 2004). Temos então uma decadência na Europa, e no Brasil uma crescente urbanização? Ou seria a primeira afirmação um exagero dramático e a segunda uma suposição naïve? O fato é que as cidades européias estão encolhendo, não somente no número de habitantes mas também em termos de infra-estrutura. Na Europa central ainda não existem favelas, mas já bairros pobres cada vez maiores, principalmente nas áreas metropolitanas mais amplas (Friedrich, van Kampen, 2004). Nesse contexto, a retórica da crise da cidade européia é virulenta. Mas como nós vimos, desde o final do Século XIX, se pode encontrar, ciclicamente, uma retórica da decadência da cidade européia, cada vez sob condições sociais transformadas. Esta retórica evidentemente continua sendo muito atraente, pelo menos para urbanistas, como se pode ver na discussão. Obviamente todos os que usam esta retórica, tem um sentimento profundo para a cidade européia. Parece que eles querem "salvá-la".

Mas qual é o motivo dessa força atraente? O que poderia ser visto como essência da cidade européia que está sendo defendido pelos seus adoradores? A característica dela é a existência de uma arquitetura antiga, pitoresca e a ausência quase completa de arranhacéus? Ou será que, com a cidade européia, estamos lidando inclusive com um mito, com uma narrativa coletiva pré-racional passada de geração em geração para assegurar-se da própria identidade? 
Recentemente, numa revisão crítica da sociologia urbana de Max Weber (1922), Walter Siebel (2004a) definiu cinco pontos como características essenciais da cidade européia:

1) A cidade européia é a diferença. Diferença do campo, diferença de cidades de outros continentes, diferença entre si. Nenhuma cidade européia é igual a outra, e nesse aspecto seriam iguais. Essa diferença se caracterizaria por uma historicidade que a cidade européia enfrenta, que está visível dentro dela. Ao contrário de outras regiões culturais, essa história não seria encarada, em primeiro lugar, como obstáculo, mas como patrimônio cultural.

2) A cidade européia é história da emancipação. O burguês, o cidadão econômico, na cidade européia se libera dos círculos econômicos fechados, assim como o citoyen, o cidadão político, se libera da dominação feudal. A cidade européia é o modelo fundamental de uma sociedade aberta da liberação econômica e política. Depois de Max Weber, Jürgen Habermas (1962) descreveu esse processo da maneira mais concisa no livro Transformação estrutural no espaço público. Ali, nos trechos de sociologia urbana, Habermas se refere aos trabalhos de Hans Paul Bahrdt (1961), que, por sua parte, se orienta na tipologia das cidades de Max Weber.

3) A polaridade entre espaço público e esfera privada representa outro princípio fundamental da cidade européia. Essa diferença, por sua vez, pode ser dividida em cinco dimensões: a social, a funcional, a jurídica, a materialsimbólica e a normativa. O espaço público como palco de frente (Goffmann, 1959) é um "lugar de comportamento estilizado, distanciado, e lugar do anonimato" (Siebel, 2004a, p. 14). Seriam as caraterísticas do nível social. $\mathrm{Na}$ dimensão funcional, o espaço público seria o lugar do mercado e da política. Em termos jurídicos, o espaço público estaria sujeito ao direito público, ao contrário do 
direito privado de um dono de um edifício. "Conformação, materiais e símbolos utilizados transfiguram e esclarecem as diferenciações jurídicas, funcionais e sociais de espaços públicos e privados" (ibidem). Na dimensão normativa o espaço público estaria caracterizado pelo acesso livre, pela "integração social sem a negação da diferença" (ibidem).

4) A confrontação produtiva com o forasteiro seria, segundo Walter Siebel, a quarta característica da cidade européia. $\mathrm{Na}$ comunicação adensada da cidade, através do contato face a face com o desconhecido, surgem inovações sociais e econômicas. A integração social dos migrantes, mesmo como a aceitação da diferença cultural, é vista como uma força produtiva da cidade.

5) E, finalmente, a cidade européia representa um modelo de desenvolvimento regulado e planejado pelo Estado Social, amortecendo a penúria social e incentivando desde sempre o desenvolvimento econômico com ferramentas de promoção econômica, isto é, subsídios.

Todos esses aspectos foram discutidos aqui. Segundo Siebel, a sua totalidade caracteriza a cidade européia. A sua totalidade, entretanto, quase não se encontra mais ali em termos sociológicos. Confirmar-se-ia, então, o discurso da decadência da cidade européia? Será que ela se dissolve num tipo universal da cidade global?

Como vimos, aspectos isolados, como o da condição de Estado Social, estão sendo ameaçados na sua existência. Outros por exemplo, o da integração de migrantes estrangeiros -, parecem ter sido solucionados de uma forma melhor no século passado nas cidades americanas, inclusive nas brasileiras, do que na Europa, onde existem bairros altamente segregados em termos étnicos. Nesse contexto, a cidade européia já acabou com a promessa da integração social. Enquanto no continente americano os migrantes da segunda geração se identificam como americanos ou brasileiros, na Europa, especialmente na Alemanha, eles se identificam como 
turcos ou algerianos, mesmo se eles nascem na Europa e quase não falam mais o idioma de seus pais (Gestring et al., 2004).

Assim, a cidade européia, muitas vezes, parece uma idéia da classe burguesa, que paira sobre a arquitetura antiga renovada dos centros, mas que pouco se refere à vida social da população que vive nela. Uma revitalização dessa idéia nas condições da globalização parece idealista, mesmo assim vários urbanistas prognosticam um futuro dela (Marcuse, 2004; Siebel, 2004a). Quem quiser salvar a cidade européia, deve revitalizar o seu espaço público, isto é, por um lado, reformar as bases do Estado de Bem-estar europeu para garantir a sua permanência; e, por outro lado, realizar finalmente uma política de integração de todos os grupos sociais da cidade, quer dizer, aspirar não somente a uma integração de uma minoria étnica na maioria da sociedade. Nesse aspecto, a cidade européia certamente poderá aprender com as cidades brasileiras.

O ideal de uma sociedade de cidadãos também poderá receber estímulos importantes do orçamento participativo. Ele representa uma prática social política que se opõe nas duas alternativas paradigmáticas da europeização, ou mais mercado ou mais Estado. Mesmo com alguns projetos alemães do programa Agenda 21 da ONU que se referem do orçamento participativo (Kern et al., 2004) e com o interesse das ONGs pelo Fórum Social Mundial, em Porto Alegre, essa inovação brasileira política e social quase não é conhecida na sociologia e na politologia da Alemanha. Pelo menos há duas obras básicas que tentam introduzir essa forma da política na discussão acadêmica (Herzberg, 2002; Zimmermann, 1999). Mas, nos institutos mais reputados se discutem os conceitos do "New Public Managment" (Naschold, Bogumil, 2001) e do "Good Governance" (Coly, Breckner, 2004). Isto é bem significado pelo interesse quase inexistente pela América Latina, em geral, e pelo Brasil, em particular, não somente nas ciências sociais e não somente na sociologia urbana. Uma exceção seriam os trabalhos, às vezes bastante românticos, de uma geração mais jovem de sociólogos sobre a auto-organização nas favelas (Lanz, 2004). Além do futebol, 
do carnaval e do samba, também o favela-chique já chegou à Europa como expressão brasileira.

Mas esses autores pelo menos tentaram aprender algo sobre a cidade brasileira, em cooperação com sociólogos brasileiros. A sociologia urbana estabelecida, ao contrário, se concentra por exemplo nos programas do Ministério da Ciência e da Sociedade de Pesquisa Alemã relacionados com a China. Isto se deve, naturalmente, ao mercado potencialmente maior (para produtos alemães). Mas também parece manifestar-se ali a incompreensão pelo fato de que a cidade européia poderia aprender algo das práticas sociais em outros continentes.

\section{Conclusão}

Na Conferência das Metrópoles, realizada em maio de 2005 em Berlim (www.metropolis2005.org), ao ser analisada uma rede informal de mais de 80 cidades com mais de um milhão de habitantes no mundo inteiro, ficou visível que os planejadores e políticos das cidades, particularmente os alemães, tendem a negar completamente os próprios problemas sociais e a querer, em vez disso, presentear o mundo com tecnologia alemã, negando o conhecimento geral da sociologia urbana, que os problemas das cidades não vão ser dissolvidos com inovações tecnológicas, mas com inovações sociais. Em face desta comunicação de mão única, que ainda hoje existe, não se pode excluir a possibilidade do declínio das cidades européias nesta trilha de desenvolvimento. Porque a história mostrou que sistemas sociais - também as cidades -, que não aprendem de seu contexto, entram em decadência (Weber, 1922). Hoje o contexto é a globalização. As cidades encolhidas possivelmente são uma primeira manifestação disso. Mas isto só é uma expressão da tendência social que as cidades européias (e, em grande parte, também a sociologia urbana européia) desenvolve como um sistema auto-referencial. A decadência da cidade européia ou a respectiva retórica só poderá ser impedida numa confrontação produtiva, em pé de igualdade com outros modelos urbanos. 


\title{
Notas
}

1 Por exemplo: de 1880 até 1910, a população cresceu em Paris de 2,2 milhões para 3 milhões, em Londres de 3,8 milhões para 7,2 milhões, em Berlim de 1,8 milhões para 3,4 milhões (Kuczynski, 1982, p. 176).

2 Em 1997, em toda Alemanha 9\% da população era de "estrangeiros" (Statistisches Bundesamt, 2000, p. 44); nas cidades grandes, o número ainda é maior: em Munich, Frankfurt e Stuttgart de 25 a 30\% e 50\% dos "estrangeiros" na Alemanha vivem em cidades com mais que 100 mil habitantes (Spiegel, 2004, p. 187).

3 Mesmo se Häußermann e Siebel (1988) já apontaram a tendência social das cidades encolhidas muito cedo, só agora - quando os efeitos às vezes parecem dramáticos -, o discurso público se refere ao problema.

\section{Decline of the European city: a social tendency or a rhetoric figure?}

\begin{abstract}
Since decades, the Urban Sociology discusses the so called decline of the European city. International social theorists, like Saskia Sassen or Manuel Castells, describe the European city as an antiquated concept which, in times of the globalization, faces no future. Recently in Germany the urban sociology stresses a new phenomenon as an expression of this development: the shrinking city. In fact, demographic data indicates a diminuation of the population in metropolitan areas. But, does this mean that the European city is declining? In a critic review of contemporary studies in German Urban Sociology, this article tries to find out whether the decline of the European city can be considered as a social tendency or merely as a rhetoric figure of a scientific discipline in crisis.
\end{abstract}

Key-words: European city, urbanism, social theory.

\section{Referências bibliográficas}

BAHRDT, Hans Paul. Die moderne Großstadt. Hamburg, 1961.

BANTEL, Claus. Im Häusermeer. São Paulos Erfahrung mit Stadtplanung und Favela-Politik. In: BLUM, Elisabeth; NEITZKE, Peter (Orgs.) 
Favela Metropolis. Berichte und Projekte aus Rio de Janeiro und São Paulo. Basel, 2004. p. 118-122.

BBB (Berliner Bäderbetriebe) Presseinformation. 2005. Disponível em: $<\mathrm{http}: / / w w w . b e r l i n e r b a e d e r b e t r i e b e . d e / d o w n l o a d s / P r e s s e m a p p e$ BBB.pdf>.

BARTHÉLEMY, M. Le vieux Paris et le nouveau. Paris, 1861.

BASTOS, Paulo. Favela-Intervention in São Paulo. In: BLUM, Elisabeth; NEITZKE, Peter (Orgs.) Favela Metropolis. Berichte und Projekte aus Rio de Janeiro und São Paulo. Basel, 2004. p. 16-42.

BERNT, Matthias. Abrissprogramm Ost. In: OSWALT, Philipp (Org.). Schrumpfende Städte. Bd. 1, Internationale Untersuchung. Ostfildern-Ruit, 2004. p. 660-665.

BLANQUI, Auguste. Critique sociale. Paris, 1885. v. 2.

BLUM, Elisabeth; NEITZKE, Peter (Orgs.) Favela Metropolis. Berichte und Projekte aus Rio de Janeiro und São Paulo. Basel, 2004.

BOCKLET, Reinhold. Leistungen der Daseinsvorsorge im Konflikt mit dem EU-Wettbewerbsrecht. In: Schader-Stiftug (Org.): Die Zukunft der Daseinsvorsorge. Öffentliche Unternehmen im Wettbewerb. Darmstadt, 2001. p. 11-24.

BODENSCHATZ, Harald. Europäische Stadt, Zwischenstadt und New Urbanism. Die Planerin. Fachzeitschrift für Stadt- Regional- und Landesplanung, n.3, 2001. Disponível em: <http://www.ceunet.de/ zwischenstadt.htm>.

BODENSCHATZ, Harald. Urban Renaissance in Birmingham und Manchester. Palestra no Centro Schinkel da Universidade Téchnica de Berlim (TU), no dia 18 do abril 2005.

CASTELLS, Manuel. The rise of the network society. Oxford, 1996. (The information age, $\mathrm{v} 1$ ).

CIAM (Congrès Internationaux d'Architectur Moderne). La Charte de Athènes. Avec un discours de Jean Giraudoux. Paris, 1943.

COLY, Anette; Elke BRECKNER. Dezentralisierung und Stärkung der kommunalen Selbstverwaltung zur Förderung von Good Governance. Aus Politik und Zeitgeschichte. Beilage zur Zeitschrift das Parlament, n. 15-16, 2004. p. 3-11.

FOURNEL, Victor. Paris nouveau et Paris futur. Paris, 1868. 
FRIEDRICHS, Jürgen; KAMPEN, Ronald van. Armutsgebiete in europäischen Großstädten - ein vergleichende Analyse. In: SIEBEL, Walter (Org.). Die europäische Stadt. Frankfurt, 2004. p. 67-84.

GESTRING, Norbert; JANßEN, Andrea; POLAT, Ayça. Integrationspfade: Die zweite Generation in den USA und Deutschland. In: SIEBEL, Walter (Org.). Die europäische Stadt. Frankfurt, 2004. p. 230243.

GOFFMANN, Erving. The presentation of self in everyday life. New York, 1959.

HABERMAS, Jürgen. Strukturwandel der Öffentlichkeit. Untersuchungen zu einer Kategorie der bürgerlichen Gesellschaft. Frankfurt, 1962.

HÄUßERMANN, Hartmut. Die Baupolitik für Berlin? In ARCHITEKTENKAMMER BERLIN (Org.). Neue Archtiektur für Berlin. Jahrbuch 2001. Hamburg, 2001. p. 46-51.

HÄUßERMANN, Hartmut; SIEBEL Walter. Neue Urbanität. Frankfurt, 1986.

. Die schrumpfende Stadt und die Stadtsoziologie. In: FRIEDRICHS, Jürgen (Org.). Soziologische Stadtforschung. Opladen, (Sonderheft der Kölner Zeitschrift für Soziologie und Sozialpsychologie), 1988. p. 75- 94.

. Festivalisierung der Stadtpolitik: Stadtentwicklung durch große Projekte. Opladen, 1993.

HERZBERG, Carsten. Wie partizipative Demokratie zu administrativen Verbesserungen führen kann. Der Bürgerhaushalt von Porto Alegre. Reihe Region-Nation-Europa Bd. 9. Münster, 2002.

HOFFMANN-AXTHELM, Dieter. Die dritte Stadt. Bausteine eines neuen Gründungsvertrages. Frankfurt, 1993. . Anleitung zum Stadtumbau. Stuttgart, 1996.

KERN, Kristine; KOLL, Claudia; SCHOPHAUS, Malte. Local Agenda 21 in Germany: An Inter and Intranational Comparison. Discussion Paper SP IV 2004-104, Wissenschaftszentrum Berlin für Sozialforschung. Berlin, 2004.

KNIE, Andreas; MARZ, Lutz. Die Stadtmaschine. Zu einer Raumlast der organisierten Moderne. Discussion Paper FS II 97-108, Wissenschaftszentrum Berlin für Sozialforschung. Berlin, 1997. 
KUCZYNSKI, Jürgen. Geschichte des Alltags des deutschen Volkes. Bd. IV, 1871-1918. Berlin, 1982.

LANZ, Stephan (Org.). City of COOP. Ersatzökonomien und städtische Bewegungen in Rio de Janeiro und Buenos Aires. Berlin, 2004.

LE CORBUSIER. Städtebau. Berlin/Leipzig, orig.1925. Tradução francesa: Urbanisme. Paris, 1929.

LEFÈBVRE, Henri. La revolution urbaine. Paris, 1970.

MARCUSE, Peter. Verschwindet die europäische Stadt in einen allgemeinen Typus der gloablisierten Stadt? In: SIEBEL, Walter (Org.). Die europäische Stadt. Frankfurt, 2004. p. 112-118.

MITSCHERLICH, Alxeander. Die Unwirtlichkeit unserer Städte. Anstiftung zum Unfrieden. Frankfurt, 1965.

NASCHOLD, Frieder; BOGUMIL, Jörg. Modernisierung des Staates. New Public Managment in deutscher und internationaler Perspektive. Reihe Grundwissen der Politik, Bd. 22, 2. vollständig aktualisierte und stark erweiterte Auflage Aufl. Opladen, 2000.

OSWALT, Philipp (Org.). Schrumpfende Städte. Bd. 1, Internationale Untersuchung. Ostfildern-Ruit, 2004.

PAMUK, Ayse; CAVALLIERI, Fernando. Das Feavela-Bairro-Programm. Neue Tendenzen bei der Aufwertung von Favelas in Rio de Janeiro. In: BLUM, Elisabeth; NEITZKE, Peter (Orgs.) FavelaMetropolis. Berichte und Projekte aus Rio de Janeiro und São Paulo. Basel, 2004. p. 16-42.

REULECKE, Jürgen. Geschichte der Urbanisierung in Deutschland. Frankfurt, 1985.

SASSEN, Saskia. The Global City: New York, London, Tokyo. Princeton, 1991.

SENNETT, Richard. The fall of the public man. New York, 1976.

SETHMANN, Jens. New Urbanism. Downtown Kitsch Town. In: Mietermagazin, n. 9, 2001. Disponível em: <http://www.berliner-mieterverein.de/magazin/online/mm0901/090124.htm>.

SIEBEL, Walter (Org.). Die europäische Stadt. Frankfurt, 2004.

SIEBEL,Walter. Einleitung. Die europäische Stadt. In: SIEBEL, Walter (Org.). Die europäische Stadt. Frankfurt, 2004a. p. 11-48. 
SPIEGEL, Erika. Die europäische Stadt - eine schrumpfende Stadt. In: SIEBEL, Walter (Org.). Die europäische Stadt. Frankfurt, 2004. p. 182-196.

STATISTISCHES BUNDESAMT (Org.). Datenreport 1999. Zahlen und Fakten über die Bundesrepublik Deutschland. Bonn, 2000.

TU (Technische Universität Berlin). Die ökonomischen Auswirkungen sind dramatisch. Interview mit Ludwig Pawlowski. In TU intern, Die Hochschulzeitung der Technischen Universität Berlin, 10/2004: 2004. Verificar se é periódico Disponível em: $<$ http://www.tu-berlin.de/presse/tui/04okt/pawlowski.htm>.

WAGNER, Martin. Das Berliner Wohungsproblem. Das Neue Berlin, Heft 3, p. 50-52, 1929a.

MARTIN, Wagner. Verkehr und Tradition. Das Neue Berlin, Heft 7, p. 129-135. 1929b.

WEBER, Max. Die Stadt. In: WEBER, Max. Wirtschaft und Gesellschaft. Tübingen, 1922. p. 513-602.

WERLE, Hermann. Monopoly auf dem Wassermarkt. Mieterecho, n. 290, Mai 2002: Disponível em: <http://www.bmgev.de/mieterecho/290/ themen/05.htm?druck $=1>$.

ZIMMERMANN, Clóvis R. Vom Paternalismus zur partizipatorischen Demokratie auf lokaler Ebene. Das Fallbeispiel des partizipatorischen Haushaltes im brasilianischen Porto Alegre. Tese (Mestrado) - Ruprecht-Karls-Universität Heidelberg, 1999. 